Rabaska

Revue d'ethnologie de l'Amérique française

\title{
L’héritage de Louis Bilodeau (1925-2006)
}

\section{Serge Gauthier}

Volume 5, 2007

URI : https://id.erudit.org/iderudit/019029ar

DOI : https://doi.org/10.7202/019029ar

Aller au sommaire du numéro

Éditeur(s)

Société québécoise d'ethnologie

ISSN

1703-7433 (imprimé)

1916-7350 (numérique)

Découvrir la revue

Citer ce document

Gauthier, S. (2007). L’héritage de Louis Bilodeau (1925-2006). Rabaska, 5,

100-102. https://doi.org/10.7202/019029ar

Ce document est protégé par la loi sur le droit d'auteur. L'utilisation des services d'Érudit (y compris la reproduction) est assujettie à sa politique d'utilisation que vous pouvez consulter en ligne.

https://apropos.erudit.org/fr/usagers/politique-dutilisation/
Cet article est diffusé et préservé par Érudit.

Érudit est un consortium interuniversitaire sans but lucratif composé de l’Université de Montréal, l'Université Laval et l'Université du Québec à Montréal. Il a pour mission la promotion et la valorisation de la recherche. https://www.erudit.org/fr/ 


\section{Nécrologie}

\section{L'héritage de Louis Bilodeau (1925-2006)}

La mort de Louis Bilodeau (1925-2006), célèbre animateur des Soirées canadiennes, nous fait particulièrement constater l'oubli presque total qui entoure aujourd'hui la mise en valeur de notre folklore sur les ondes de la télévision. Heureusement, les Soirées canadiennes de Louis Bilodeau sont désormais disponibles sur DVD. Elles sont aussi à nouveau diffusées sur la chaîne Prise 2 et Louis Bilodeau a pu voir cela avant de mourir. L'animateur a dû se réjouir de la renaissance d'un folklore ainsi préservé presque miraculeusement grâce à lui. En effet, les participants et participantes de cette

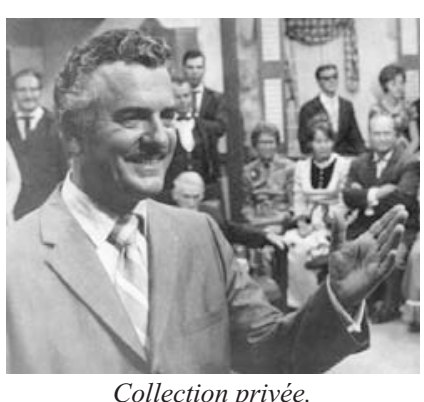

Collection privée. émission sont aujourd'hui pour la plupart disparus et ils ont pu grâce à ses Soirées canadiennes léguer cette tradition dont ils étaient un peu les derniers dépositaires. Voilà bien le fond du problème : où est aujourd'hui la continuité en ce domaine ? Notre folklore occupe désormais peu de place au sein de la société québécoise et est à peu près oublié. Il n'existe plus depuis belle lurette d'émissions de folklore à la télévision ou même à la radio. Et pourtant ce folklore reste encore un des traits essentiels de l'héritage des Français d'Amérique.

\section{Une tradition continue}

Il ne faut pas oublier que Louis Bilodeau était lui aussi un héritier. La formule de son émission faisait revivre pour l'essentiel l'atmosphère des soirées familiales ou villageoises d'autrefois. Ce folklore devenant pour nos ancêtres d'après la Conquête de 1760 une manière parmi d'autres de résister en français au sein d'un continent devenu anglophone. Plus tard, avec le $\mathrm{XIX}^{\mathrm{e}}$ et le $\mathrm{XX}^{\mathrm{e}}$ siècle, les Soirées canadiennes se sont déplacées en milieu urbain. L'arrivée massive de francophones à Montréal au début $\mathrm{du} \mathrm{xx}^{\mathrm{e}}$ siècle permettait la tenue de ces activités fort populaires et un peu nostalgiques. Il faut penser ici 
aux Soirées de folklore de Conrad Gauthier où se produisait notamment La Bolduc et l'incomparable folkloriste qu'était Ovila Légaré.

Il y eut aussi une tradition universitaire en ce domaine. Marius Barbeau (1883-1969) a tenu à plusieurs reprises des Soirées de folklore notamment au Château Frontenac à Québec. Cette approche a ensuite été relayée vers l'Université Laval avec les Archives de folklore créées en 1944 par Luc Lacourcière (1910-1989) et Félix-Antoine Savard (1896-1982). Un chercheur en folklore important de l'Université Laval, Conrad Laforte, toujours vivant, mais un peu oublié en son pays, est même devenu un sommité internationale en chanson folklorique française.

Voilà bien le riche courant de mise en valeur du folklore traditionnel dans lequel s'inscrit Louis Bilodeau avec ses Soirées canadiennes. Ce pionnier de la télévision a su transmettre à des générations de Québécois (de 1960 à 1983) l'amour des traditions nationales et aussi leur a permis de survivre un peu plus longtemps grâce à la magie de la télévision. Et toujours avec d'impressionnantes cotes d'écoute. Louis Bilodeau a réalisé cela à partir d'un poste régional des Cantons de l'Est et il a même fini par percer dans les stations montréalaises avec le temps. Un succès vraiment impressionnant.

\section{Une approche périmée}

Bien sûr, l'approche de Louis Bilodeau a pu paraître périmée aux diffuseurs du début de la décennie 1980. Cette formule où toute une localité fêtait son folklore avec l'animateur n'était plus vraiment au goût du jour. Il y avait le curé, le maire, les aînés de la paroisse et des chansons et des danses racontant à chaque semaine un Québec pourtant réel - et je ne dirai pas profond - qui ne trouve plus grand écho de nos jours dans les médias en général.

Il allait de soi que, dans le Québec de l'après-référendum de 1980, le folklore québécois faisait un peu mal. Il avait tellement été brandi comme emblème dans la décennie 1970 que l'on ne voulait plus le voir. Les chansonniers québécois ont presque tous connu alors une période creuse. C'est dans ce contexte aussi que les Soirées canadiennes de Louis Bilodeau sont disparues après 23 années de diffusion. Elles ne furent pas remplacées. Il n'y a pas eu de vraie présence de notre folklore sur les ondes de la télévision depuis. Et cela est fort dommage...

\section{Un héritage}

Il faut donc saluer Louis Bilodeau. Il laisse un bel héritage. Souhaitons un bon succès au DVD de ses Soirées canadiennes ! Peut-être mériteraientelles aussi une place dans nos écoles... Mais, plus encore, je pense que l'héritage de Louis Bilodeau sera vraiment relancé le jour où une émission 
de télévision viendra à nouveau présenter le folklore d'ici au petit écran. Sans doute cela aurait vraiment fait plaisir à Louis Bilodeau et je ne doute pas qu'il existe encore un public intéressé par notre folklore. Cette nouvelle émission de folklore ne ressemblerait pas nécessairement aux Soirées canadiennes de Louis Bilodeau : la mise en valeur du folklore doit évoluer à l'intérieur des sociétés comme tout autre trait culturel. Et cela me semble vraiment important pour la conservation de cet héritage culturel unique.

Serge Gauthier Centre de recherche sur l'histoire et le patrimoine de Charlevoix 